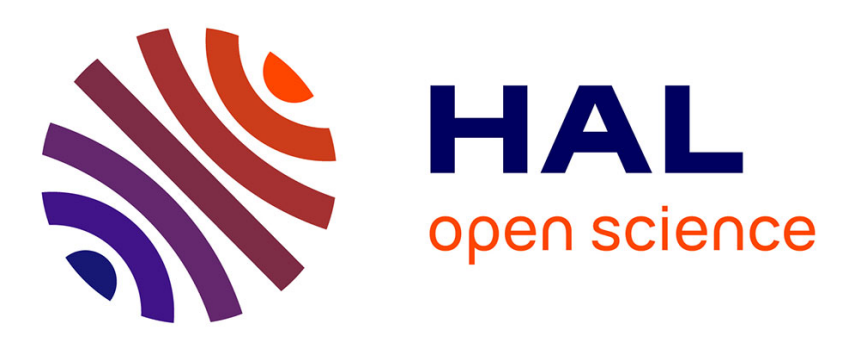

\title{
Novel WDM-PON Architecture for Simultaneous Transmission of Unicast Data and Multicast Services
}

\author{
Min Zhu, Shilin Xiao, Wei Guo, Weisheng Hu, Benoit Geller
}

\section{To cite this version:}

Min Zhu, Shilin Xiao, Wei Guo, Weisheng Hu, Benoit Geller. Novel WDM-PON Architecture for Simultaneous Transmission of Unicast Data and Multicast Services. Communications and Photonics Conference and Exhibition (ACP), 2009 Asia, Nov 2009, Shanghai, China. 10.1117/12.851337 . hal01229112

HAL Id: hal-01229112

https://hal-ensta-paris.archives-ouvertes.fr/hal-01229112

Submitted on 16 Nov 2015

HAL is a multi-disciplinary open access archive for the deposit and dissemination of scientific research documents, whether they are published or not. The documents may come from teaching and research institutions in France or abroad, or from public or private research centers.
L'archive ouverte pluridisciplinaire HAL, est destinée au dépôt et à la diffusion de documents scientifiques de niveau recherche, publiés ou non, émanant des établissements d'enseignement et de recherche français ou étrangers, des laboratoires publics ou privés. 


\title{
Novel WDM-PON Architecture for Simultaneous
}

\section{Transmission of Unicast Data and Multicast Services}

Min Zhu* (朱敏) ${ }^{1,2}$, Shilin Xiao (肖石林) ${ }^{1}$, Wei Guo (郭薇) ${ }^{1}$, Weisheng Hu (胡卫 生) ${ }^{1}$ and Benoit Geller ${ }^{2}$

${ }^{1}$ State Key Lab of Advanced Optical Communication Systems and Networks, Department of Electronic Engineering, Shanghai Jiao Tong University, No. 800, Road Dongchuan, Shanghai 200240, China,

${ }^{2}$ Lab of Electronics and Computer Engineering, ENSTA ParisTech, No. 32, boulevard Victor, 75739, Paris, France

E-mail: zhuminxuan@sjtu.edu.cn

Abstract: We propose a novel WDM-PON to simultaneously transmit unicast data and multicast services with upstream data re-modulation in optical network units (ONUs). In the optical line terminal (OLT), for each wavelength channel, the downstream unicast data is applied to one arm of a dual-parallel Mach-Zehnder modulator (DPMZM), to generate baseband unicast non-return-to-zero (NRZ) signal, while a radio frequency $(\mathrm{RF})$ control signal is applied to other arm of a DPMZM to present two un-modulated sidebands for multicast data modulation in differential-phase-shift keying (DPSK) format. By simply switching on/off the RF control signal, the flexible and dynamic multicast services are realized. The proposed scheme is experimentally demonstrate with $1.25-\mathrm{Gb} / \mathrm{s}$ downstream unicast, multicast and upstream data.

OCIS codes: (060.4255) Networks, multicast; (060.4510) Optical

communications

Key words: WDM-PON; multicast; sub-carrier multiplexing (SCM); differentialphase-shift keying (DPSK).

\section{二种新型 WDM-PON 系统中同时传输单播数据和组播业务}

\author{
朱敏 ${ }^{1,2}$, 肖石林 ${ }^{1}$, 郭薇 ${ }^{1}$, 胡卫生 ${ }^{1}$, Benoit Geller $^{2}$ \\ ${ }^{1}$ 区域光纤通信网和新型光通信系统国家重点实验室 电子工程系 上海交通大学 \\ 上海市东川路 800 号 200240 上海
}


${ }^{2}$ 电子与计算机工程实验室 国立高等先进技术学校 (巴黎高科) 75739 巴黎 法 国

摘要: 本文提出一种新型的 WDM-PON 系统, 用于同时传输单播数据和组 播业务, 并在光网络单元中实现了上行数据重调制。光线路终端中, 针对每一个 波长载波通道, 下行单播数据加载到双并行马赫曾德调制器的一个臂上, 产生基 带单播非归零码信号; 而射频控制信号加载到双并行马赫曾德调制器的另一个臂 上, 产生两个未调制的光边带, 用于承载差分相移键控调制格式的组播业务。通 过简单开关切换射频控制信号, 实现了灵活动态的组播业务。在提出的系统方案 中, 实验演示了 $1.25-\mathrm{Gb} / \mathrm{s}$ 的下行单播数据、组播业务和上行单播数据的传输。

关键字: 波分复用无源光网络; 组播; 副载波复用; 差分相移键控调制。

\section{Introduction}

Wavelength-division multiplexed passive optical network (WDM-PON) is regarded as a promising broadband access solution because of its almost unlimited bandwidth, network security, simple management and upgradeability [1], [2]. In WDM-PON, some customers may subscribe the diverse services such as high-definition television (HDTV) and video-on-demand (VoD) in a particular duration of time. To simultaneously delivery point-to-multipoint multicast video services and conventional unicast data in WDM-PON, some efforts have been reported [3]-[7], and fall into the following two categories: 1) In-band transmission, the multicast data are orthogonally modulated onto the unicast signals by adjusting extinction ratios (ER) of the unicast signals [3], [4], or by dynamically conversing unicast data modulation format [5], which require complicated timing and synchronization; 2) Out-of-band transmission, multicast data in the sub-carrier multiplexing (SCM) format is overlaid on baseband unicast data with the amplitude shift keying (ASK) modulation in the same wavelength channel, by dynamically adjusting ER of the unicast ASK signals [6], [7], which require high-frequency electronic components at both the transmitter and receiver sides. 
In this paper, we propose and demonstrate a novel WDM-PON to simultaneously deliver the downstream unicast data and multicast services along with upstream data re-modulation in optical network units (ONUs). In the optical line terminal (OLT), for each wavelength channel, the downstream unicast data is applied to one arm of a dual-parallel Mach-Zehnder modulator (DPMZM), to generate unicast non-returnto-zero (NRZ) signal carried on the optical baseband carrier, while a radio frequency (RF) control signal is applied to other arm of a DPMZM to produce two un-modulated optical sidebands for subsequent multicast data modulation in differential-phase-shift keying (DPSK) format. By simply switching on/off the RF control signal in each wavelength channel, the multicast data can be enabled to realize flexible and dynamic multicast overlay. The upstream data re-modulation based on the downstream baseband NRZ unicast signal is also experimentally demonstrated in ONUs.

\section{Principle of proposed WDM-PON}

The proposed WDM-PON architecture with SCM multicast overlay is shown in Fig. 1. In the OLT, the downstream carrier of each wavelength channel is generated by a continuous-wave (CW) laser, and then modulated by a DPMZM [8]. The DPMZM consists of a pair of $\mathrm{x}$-cut LiNbO3 Mach-Zehnder modulators (MZMs) embedded in the two arms of a main MZM structure. The DPMZM has three bias ports, which belongs to the two sub-MZMs and the main modulator respectively. The downstream unicast data is applied to one arm of a DPMZM, to generate a downstream unicast NRZ signal with a lower extinction ratio (ER); while a RF control signal is applied to the other arm of the DPMZM to switch on/off two un-modulated optical sidebands. These optical double sideband signals in all wavelength channels are then coupled by an arrayed waveguide grating (AWG) and subsequently modulated by a phase modulator (PM), which is driven by the multicast data to overlay a multicast DPSK signal on the optical sub-carriers. It should be noted that the multicast data are also superimposed onto the optical baseband carrier carrying the downstream unicast data, but the part of multicast data are not recovered in the ONU. Hence, the multicast and unicast data transmission differ in both frequency and modulation format, which avoids the bit synchronization between them.

When an ONU on a wavelength makes a request for multicast services, the RF control signal on the corresponding wavelength channel is switched on, which allows 
for simultaneous modulation of multicast data on the optical sub-carriers. To disable the multicast data for a designated ONU user, the RF control signal is simply switched off and consequently the optical sub-carriers for multicast data modulation do not exist. Thus the multicast data can be flexibly and dynamically transmit to destined ONU users, by simply switching on/off the RF control signal in the OLT.

After transmission over fiber, an AWG in the remote node (RN) is used to de-multiplex the downstream wavelengths and route them to individual ONUs. At the ONU, a circulator and fiber Bragg grating (FBG) are employed to separate the downstream unicast NRZ data and the multicast DPSK data on the different spectra. The multicast data are demodulated by a 1-bit Mach-Zehnder delay interferometer (MZDI) followed by a low-speed photo-detector (PD). The baseband optical carrier is filtered and split into two parts: one is detected by a PD receiver for downstream unicast data; the other part of the baseband carrier power is fed into a single drive MZM for upstream data re-modulation and sent back to the OLT through another feeder fiber. In this way, ONU module without light source deployment could also be implemented. It is an attractive feature for PON deployment. It is noted that all the multicast control intelligence is deployed at the OLT by simply switching on/off the RF control signal, which is transparent to all ONUs and hence can be a cost-effective solution.

\section{Experimental setup and results}

To verify the feasibility of the proposed WDM-PON with SCM multicast overlay, we perform an experiment as shown in Fig.2. In the OLT, a continue wave (CW) light in the $1561.16 \mathrm{~nm}$ wavelength is fed into a DPMZM. One arm of DPMZM is biased at the transmission null point and driven by a $1.25-\mathrm{Gb} / \mathrm{s}$ data with a pseudo-random bit sequence (PRBS) length of $2^{31}-1$ to generate downstream unicast NRZ signal with the lower ER around 3dB. By switching on/off the 12.5-GHz RF control signal applied on another arm of DPMZM, which is also biased at the transmission null point, it is easy to control the presence of two un-modulated sub-carriers. The bias of main MZM structure is adjusted to obtain zero phase difference between two arms of modulator. Then the two signals form two sub-MZMs are combined constructively to achieve a double sideband signal at the output port of the main modulator. $A$ following PM is driven by another $1.25-\mathrm{Gb} / \mathrm{s} 2^{31}-1$ PRBS to generate multicast DPSK 
signal carried on the two optical sidebands. In the inset (i) spectra in Fig.2, when the RF control signal is switched on, an optical double-sideband signal including a baseband carrier and two sub-carriers are turned out and the sideband-to-carrier ratio (SCR) is nearly $10 \mathrm{~dB}$. Otherwise, just optical baseband carrier is displayed in inset (ii) with the multicast services switched off. Since the unicast and multicast data differ in optical spectra, the synchronization between both data is not necessary. The output from the PM is amplified by an erbium-doped fiber amplifier (EDFA) and filtered by a tunable band-pass filter (BPF) with a bandwidth of $0.4 \mathrm{~nm}$ before $12.5-\mathrm{km}$ single mode fiber (SMF) transmission.

In the ONU, an optical circulator is connected to a FBG with a 3-dB bandwidth of $0.15 \mathrm{~nm}$ and a $90 \%$ reflection ratio. The FBG is used to reflect the baseband optical carrier of unicast NRZ data and bypass the two sideband optical carriers for multicast DPSK data. After demodulated by 1-bit MZDI followed by a low speed PD with a 2.5-GHz bandwidth, the $25-\mathrm{GHz}$ oscillation of the SCM multicast data is filtered and the electrical eye diagrams of multicast data is displayed in the inset (iii). The reflected optical power of baseband NRZ signal is split into two parts by a power of splitter (POS). One half is converted to the electrical signal using a 2.5-GHz PD receiver. The detected electrical eye diagrams of downstream unicast NRZ data are shown in inset (iv). Another half of baseband power is used for $1.25-\mathrm{Gb} / \mathrm{s}$ upstream data re-modulation in the NRZ format with the higher ER around 10dB and sent back to the OLT, where it is detected by a PD.

The bit-error-rate (BER) measurement results are provided in Fig. 3 and Fig. 4. For the downstream unicast NRZ data when the RF control signal is switched on and off, the power penalties are $\sim 0.27 \mathrm{~dB}$ and $\sim 0.23 \mathrm{~dB}$, respectively. The detected electrical eye diagrams are also provided in inset of Fig. 3 in the two transmission cases, respectively. For the multicast DPSK signal on the two optical sidebands, the power penalty is $\sim 0.2 \mathrm{~dB}$ and the eye diagrams are shown in Fig. 4 a). The BER performance of upstream re-modulated NRZ signal shown in Fig. 4 b) indicates that the upstream transmission suffers $\sim 0.35-\mathrm{dB}$ penalty due to the dispersion. The eye diagram of upstream data for BTB transmission and after the 12.5-km SMF transmission are also displayed in inset of Fig.4 b).

\section{Power budgets analysis}


To verify the feasibility of the downstream link, power budgets analysis for downstream unicast and multicast data are carried out using a modulated optical power of around $-14 \mathrm{dBm}$ and $-16 \mathrm{dBm}$ as shown in Table 1 , respectively. In this analysis, EDFA gain is about $30 \mathrm{~dB}$ in the OLT. The total losses were made of a band-pass filter (BPF) loss of $3 \mathrm{~dB}$, a $6 \mathrm{~dB}$ insert loss for phase modulator, an insert loss of $5 \mathrm{~dB}$ for AWG, a $2.8 \mathrm{~dB}$ transmission loss for $12.5 \mathrm{~km}$ optical fiber, an insert loss of $0.8 \mathrm{~dB}$ for optical circulator, a $0.6 \mathrm{~dB}$ FBG insert loss, a $6 \mathrm{~dB}$ insertion loss for

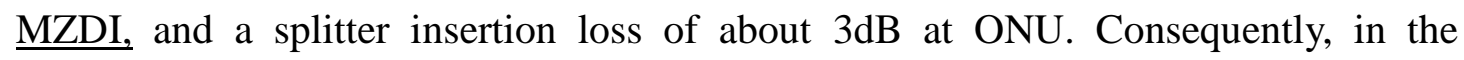
upstream power budgets analysis, a re-modulated upstream unicast signal has optical power of around $-19 \mathrm{dBm}$, according to the received downstream power. The receiver sensitivity of the downstream unicast data, multicast data and upstream unicast data are considered to be $-18.85 \mathrm{dBm},-17.25 \mathrm{dBm}$ and $-15.35 \mathrm{dBm}$ respectively, according to the experiment data (see Fig. 3 a), Fig. 4 a) and b)). The power margin of about $\underline{8.65 \mathrm{~dB}, 2.05 \mathrm{~dB} \text { and } 10.55 \mathrm{~dB}}$ are obtained for downstream unicast data, $\underline{\text { multicast data }}$ and upstream signal respectively, which indicates the feasibility of the larger transmission scope in the proposed WDM-PON.

\section{Conclusion}

We propose a novel WDM-PON to simultaneously transmit conventional unicast data and point-to-multipoint multicast services with upstream data re-modulation in ONUs. The baseband optical carrier bears the downstream unicast NRZ data, while the two optical sub-carriers only carry the multicast DPSK data. The multicast function for all wavelength channels can be quickly and dynamically reconfigured with simple and centralized management in the OLT. The feasibility of the proposed WDM-PON architecture is demonstrated experimentally with $1.25-\mathrm{Gb} / \mathrm{s}$ downstream unicast/ multicast data and 1.25-Gb/s upstream re-modulated signal.

\section{Acknowledgement}

The work was jointly supported by the National Nature Science Fund of China (No. 60972032 and No.60632010) and the National "863" Hi-tech Project of China (No. 2006AA01Z251 and No. 2007AA01Z271).

\section{References}

[1] G. Shou, Y. Hu, Z. Guo, Z. Qian, "Spectrum Sliced Wavelength Division 
Multiplexed Passive Optical Networks and Effects of Chromatic Dispersion," ACTA OPTICA SINICA, vol. 29, no. 2, pp. 312-315, Feb. 2009. (in Chinese)

[2] W. Li, L. Chen, D. Huang, "Design and Implementation of an Array Optical Receiver Device of Density Wavelength Division Multiplexing-PIN-TIA for Wavelength-Division Multiplexing Passive Optical Networks," CHINESE JOURNAL OF LASERS, vol. 35, no. 1, pp. 82-86, Jan. 2008. (in Chinese)

[3] Y. Zhang, N. Deng, C. K. Chan, and L. K. Chen, "A multicast WDM-PON architecture using DPSK/NRZ orthogonal modulation,” IEEE Photon. Technol. Lett., vol. 20, no. 17, pp. 1479-1481, Sep. 1, 2008.

[4] L. Cai, Z. Liu, S. Xiao, M. Zhu, R. Li, and W. Hu, "Video-Service-Overlaid Wavelength-Division-Multiplexed Passive Optical Network,” IEEE Photon. Technol. Lett., vol. 21, no. 14, pp. 990-992, July 15, 2009.

[5] N. Deng, C. K. Chan, L. K. Chen, and C. Lin, "A WDM passive optical network with centralized light sources and multicast overlay," IEEE Photon. Technol. Lett., vol. 20, no. 2, pp. 114-116, Jan. 15, 2008.

[6] M. Khanal, C. J. Chae, and R. S. Tucker, "Selective broadcasting of digital video signals over a WDM passive optical network," IEEE Photon. Technol. Lett., vol. 17, no. 9, pp. 1992-1994, Sep. 2005.

[7] Q. Chang, J. Gao, Q. Li, and Y. Su, "Simultaneous transmission of point-to-point data and selective of video services in a WDM-PON using ASK/SCM modulation format," OFC/NFOEC 2008, Paper OWH2.

[8] K. Higuma, S. Oikawa, Y. Hashimoto, H. Nagata, and M. Izutsu, "X-cut lithium niobate optical single-sideband modulator," Electron. Lett., vol. 37, no. 8, pp. 515-516, Apr. 2001.

\section{Figure captions}

Fig. 1 Schematic diagram of the proposed WDM-PON architecture with SCM multicast overlay. OLT: optical line terminal; RN: remote node; ONU: optical network unit; DPMZM: dual-parallel Mach-Zehnder modulator; AWG: arrayed 
waveguide grating; PC: polarization control; PM: phase modulator; LD: laser diode; PD: photodiode; RF: radio frequency; SMF: single mode fiber; FBG: fiber Bragg grating; POS: power of splitter; MZDI: Mach-Zehnder delay interferometer.

Fig. 2 Experimental setup of the proposed WDM-PON with SCM multicast overlay.

Fig. 3 BER curves and eye diagrams: (a) downstream unicast NRZ signal when the RF control signal is switched on; (b) downstream unicast NRZ signal when the RF control signal is switched off.

Fig. 4 BER curves and eye diagrams: (a) multicast DPSK data; (b) upstream re-modulated NRZ signal.

Table.1 Power margin calculation for downstream and upstream data

\section{Figures}

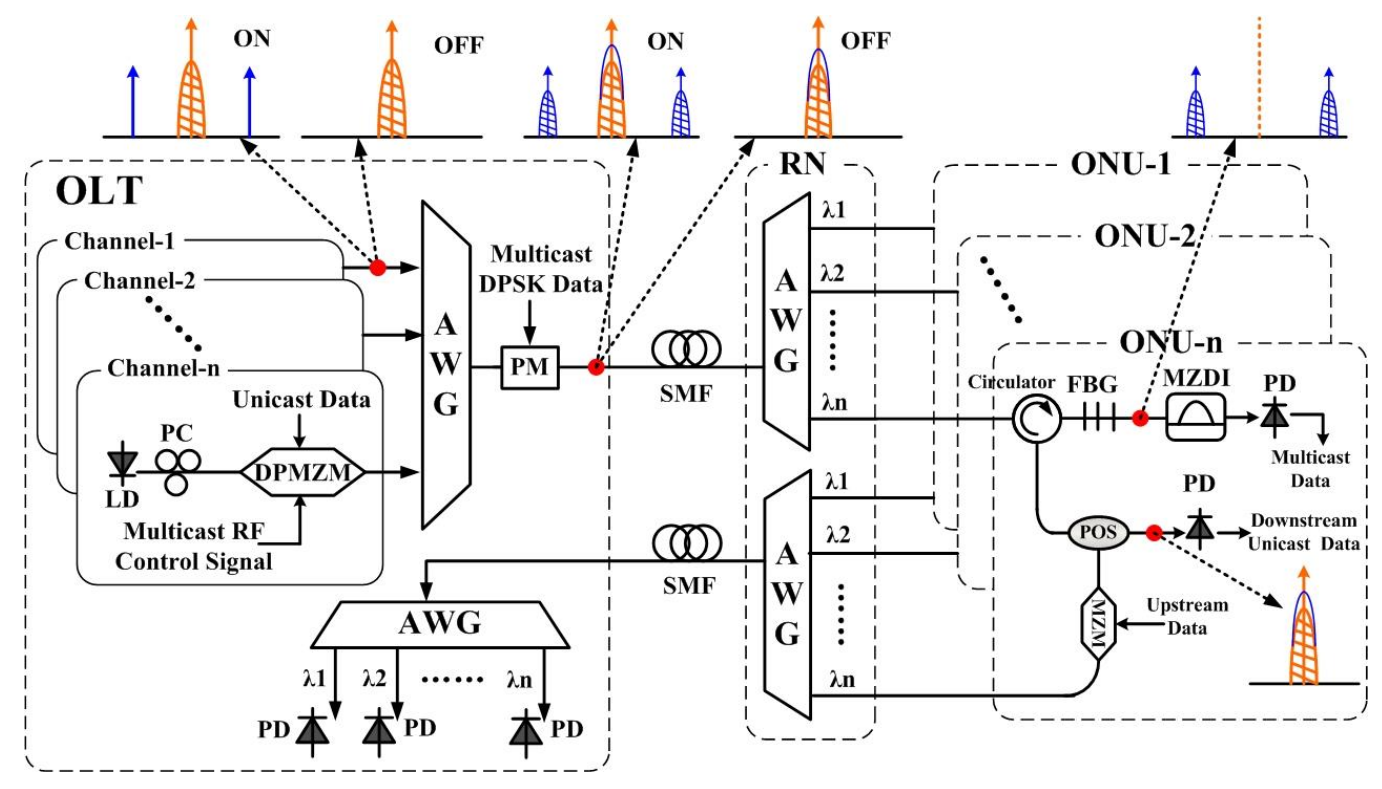

Fig. 1 Schematic diagram of the proposed WDM-PON architecture with SCM multicast overlay. OLT: optical line terminal; RN: remote node; ONU: optical network unit; DPMZM: dual-parallel Mach-Zehnder modulator; AWG: arrayed waveguide grating; PC: polarization control; PM: phase modulator; LD: laser diode; PD: photodiode; RF: radio frequency; SMF: single mode fiber; FBG: fiber Bragg grating; POS: power of splitter; MZDI: Mach-Zehnder delay interferometer. 


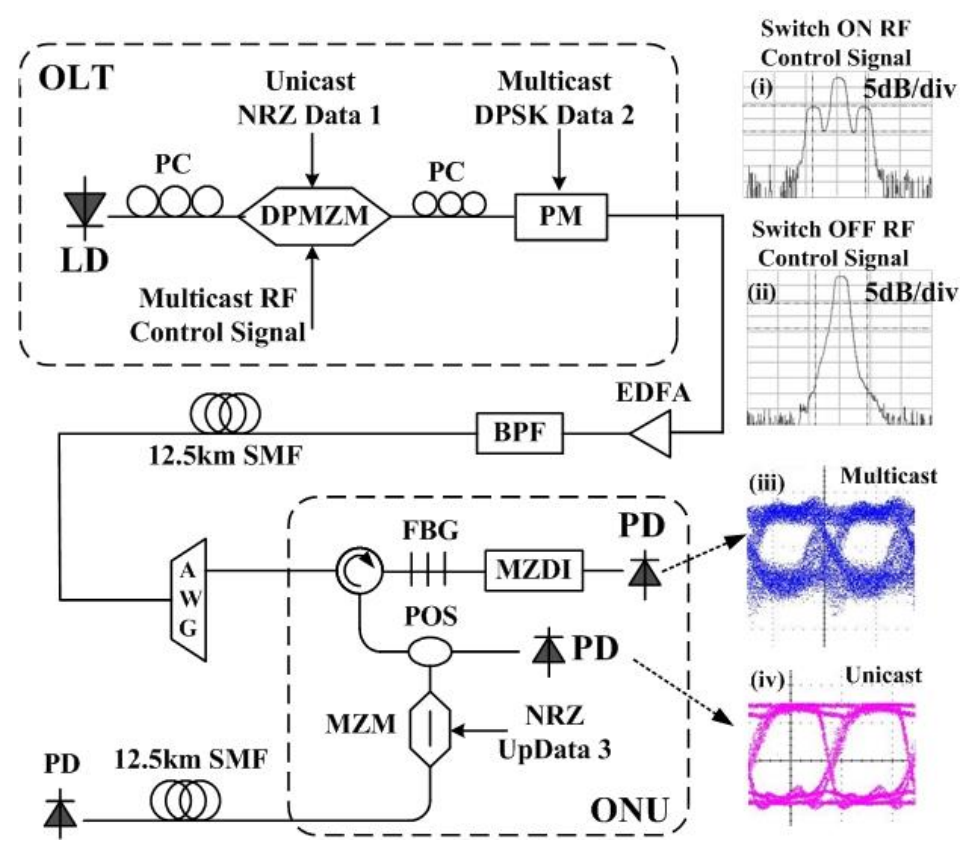

Fig. 2 Experimental setup of the proposed WDM-PON with SCM multicast overlay.
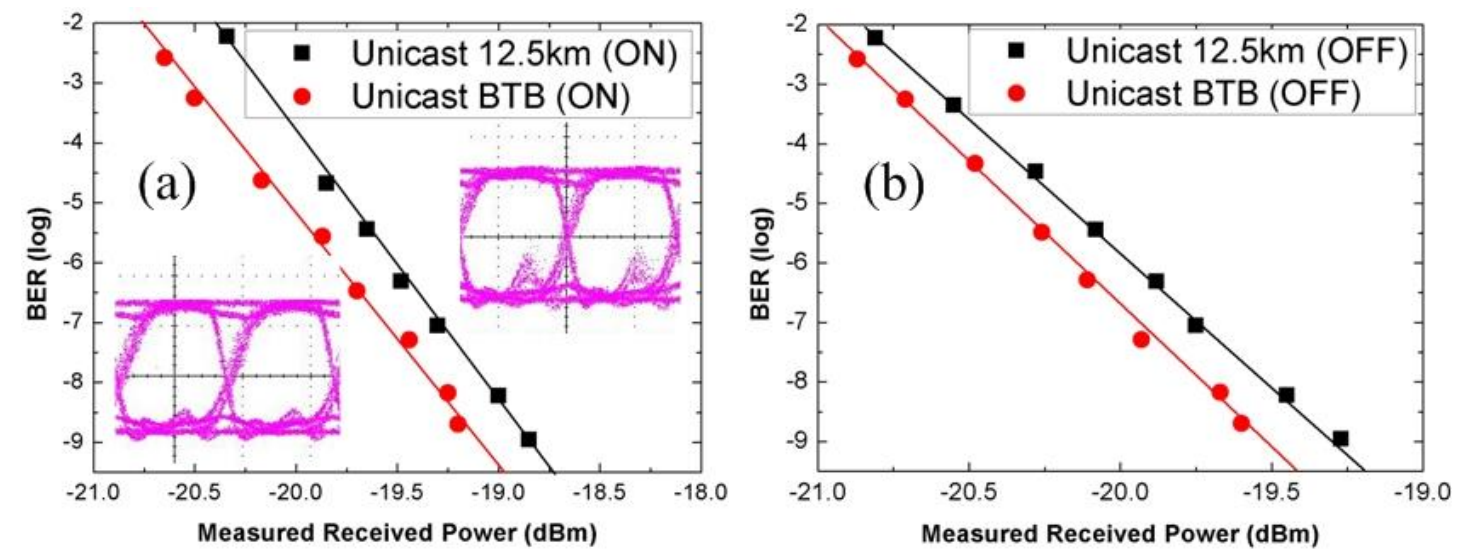

Fig. 3 BER curves and eye diagrams: (a) downstream unicast NRZ signal when the RF control signal is switched on; (b) downstream unicast NRZ signal when the RF control signal is switched off. 

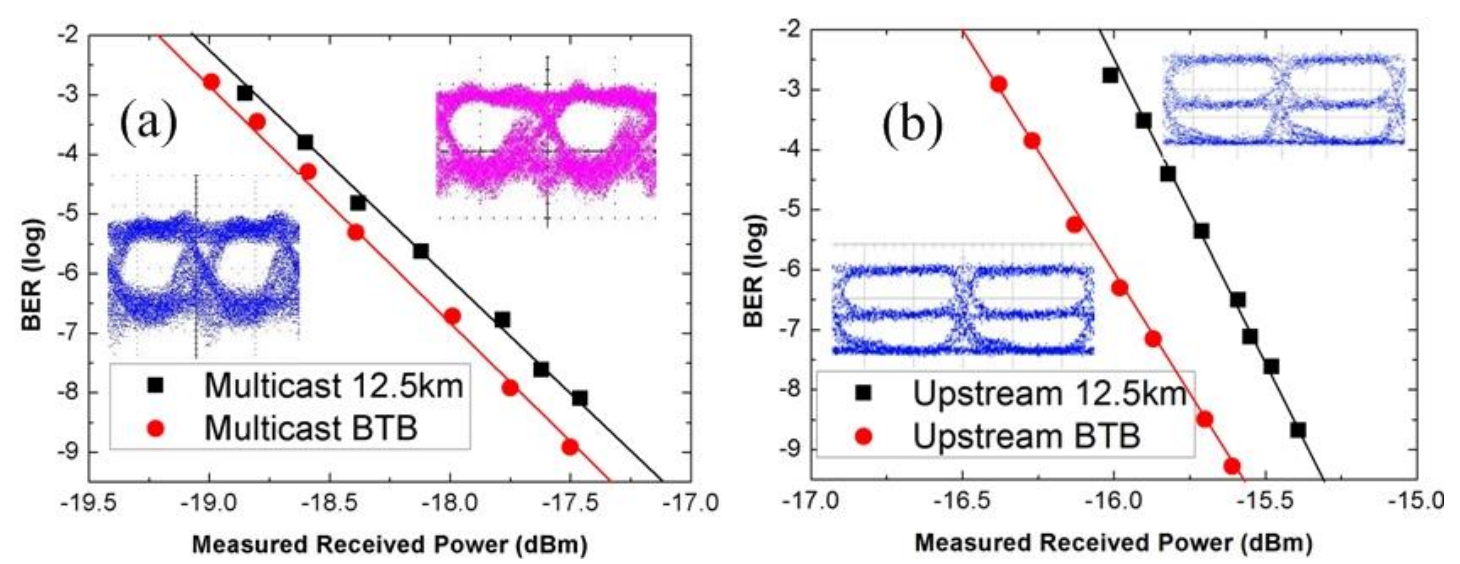

Fig. 4 BER curves and eye diagrams: (a) multicast DPSK data; (b) upstream re-modulated NRZ signal.

Table.1 Power margin calculation for downstream and upstream data

\begin{tabular}{lccc}
\hline \hline & $\begin{array}{c}\text { Downstream } \\
\text { Unicast Data }\end{array}$ & $\begin{array}{c}\text { Multicast } \\
\text { Data }\end{array}$ & $\begin{array}{c}\text { Upstream } \\
\text { Unicast Data }\end{array}$ \\
\hline Modulated power at $O L T(d B m)$ & -14 & -16 & ---- \\
Modulated power at $O N U(d B m)$ & ---- & & -19 \\
EDFA amplifier gain $(d B)$ & 30 & 30 & 30 \\
\hline BPF loss $(d B)$ & 3 & 3 & 3 \\
Phase modulator loss $(d B)$ & 6 & 6 & ---- \\
AWG insertion loss $(d B)$ & $5 \times 2^{\text {a }}$ & $5 \times 2^{\text {a }}$ & $5 \times 2^{\text {a }}$ \\
12.5km SMF loss $(d B)$ & 2.8 & 2.8 & 2.8 \\
Circulator insertion loss $(d B)$ & 0.8 & 0.8 & ---- \\
FBG insertion loss at $O N U(d B)$ & 0.6 & 0.6 & ---- \\
Splitter insertion loss at $O N U(d B)$ & 3 & ---- & ---- \\
MZDI insertion loss at $O N U(d B)$ & ---- & 6 & --- \\
\hline Insertion loss $(d B)$ & 26.2 & 29.2 & 15.8 \\
Receiver Sensitivity $(d B m)$ & -18.85 & -17.25 & -15.35 \\
Power Margin $(d B)$ & 8.65 & 2.05 & 10.55 \\
\hline \hline
\end{tabular}

a " $\times 2$ " means the optical signal experiences the loss twice. 